\title{
Chapter 4: Macrofaunal sediment selectivity considerations for beach nourishment programmes
}

Joke Van Tomme, Sarah Vanden Eede, Jeroen Speybroeck, Steven Degraer, Magda Vincx (2012) Macrofaunal sediment selectivity considerations for beach nourishment programmes.

Published in: Marine Environmental Research 84:10-16

Joke Van Tomme is the first author of this article. Sarah Vanden Eede helped with the experimental work, the analysis of the results and the finalisation of the manuscript. 


\begin{abstract}
Nowadays, beach nourishment is widely considered as a better alternative compared to the construction of hard structures to protect a sandy coast against detrimental erosive effects, both from an ecological and an engineering perspective. The rare studies conducted on the ecological impact of beach nourishment are short-term, post hoc monitoring investigations of the benthic macrofauna. Little is known of the biological processes during and after nourishment. To allow swift recolonization after nourishment, the characteristics of the nourished beach have to match the habitat demands of the benthic macrofauna. The sediment preference of the key intertidal species Scolelepis squamata, Eurydice pulchra, Bathyporeia pilosa and Bathyporeia sarsi, which dominate many West European sandy beaches, was investigated through laboratory experiments, both in single-species as well as combined-species treatments. While the former aimed at developing guidelines for impact mitigation of beach nourishment, the latter aimed at elucidating the role of biotic interactions in sediment preference. Results of the experiments indicated that Bathyporeia pilosa and Eurydice pulchra prefer the finest sediment, while Bathyporeia sarsi had a broader preference and also occurred in medium-coarse sediments. However, the sediment preference of Eurydice pulchra for fine sediments was not confirmed by other field and experimental studies. The polychaete Scolelelpis squamata had the broadest preference and even showed a high occurrence in coarse sediments that are not naturally occurring on the sandy beaches where the animals were caught for this experiment. However, this polychaete is a cosmopolitan species, not only occurring on fine-grained beaches, but also on coarse-grained beaches worldwide. The preferences imply that beach nourishment with coarse sediment will have a major effect on Bathyporeia pilosa while effects of coarse sediments on Scolelepis squamata will be minor. Finally, interspecific competition with the sympatrically occurring amphipod Bathyporeia sarsi was found to change the sediment selection of the amphipod Bathyporeia pilosa towards the coarser sediments where Bathyporeia sarsi occurred in lower frequencies.
\end{abstract}

Keywords: beaches, benthos, beach nourishment, environmental impact, sediment, macrobenthos, ecosystem management 


\section{Introduction}

Beach nourishment is an episodic, dramatic event for the sandy beach ecosystem with diverse impacts (Speybroeck et al. 2006a) both on organisms inhabiting the beach (Jones et al. 2008; Leewis et al. 2012; Schlacher et al. 2012) as well as on adjacent ecosystems (Jordan et al. 2010). However, effects depend on a variety of diverse characteristics of the specific nourishment programme. The choice between highshore, foreshore or profile nourishment greatly determines what species communities on the beach are influenced while the frequency between different nourishment projects is essential for the recovery of the system. In addition, the timing of the nourishment deserves careful consideration to maximally avoid periods of breeding or recruitment of different sandy beach organisms (Melvin et al. 1991; Peterson et al. 2000; Peterson \& Manning 2001). As beach nourishment, supplying several tons of sediment on the intertidal beach, does not allow any survival of macrobenthic infauna (Schlacher et al. 2012), attempts to bring the post-nourishment beach back to pre-nourishment ecosystem conditions, have to address postimpact restoration. Two major process-related elements seem to be of importance for swift recolonization: (1) dispersal capacities and (2) habitat demands of the species. The first aspect is related to species-specific characteristics, albeit local geography and hydrodynamics of the area surrounding the nourished beach will play an important role. Large anthropogenic structures like harbor walls may hamper long-shore drift of pelagic larvae and water column dispersal of subadult and adult organisms. Once the nourished beach has been reached, animals will have to be able to settle, burrow and survive. All this will depend on their specific tolerances and preferences, in relation to the encountered habitat. Although peer-reviewed studies on the effect of beach nourishment are scarce (Jones et al. 2008; Leewis et al. 2012; Schlacher et al. 2012), several studies have investigated the effects after dredging (Somerfield et al. 1995; Radenac et al. 1997; Savage et al. 2001; Byrnes et al. 2004; Diaz et al. 2004; Witt et al. 2004; Powilleit et al. 2006), thereby demonstrating that benthic macrofauna frequently show changes in abundance, species richness and community structure. The negative effects may either be small, with a short period of recovery in some regions (Van Dolah et al. 1984; Radenac et al. 1997; Roberts \& Forrest 1999), since macrofauna of dynamic coastal zones is tolerant to disturbances (Newell et al. 1998), or may be highly important, permanently altering the macrobenthic association (Harvey et al. 1998). Structural damages on the macrofauna may occur due to changes in the granulometric characteristics, since the macrofauna composition is closely related to the sediment characteristics (McLachlan 1996; Brazeiro 2001; McLachlan \& Brown 2006). Indeed, sediment composition is a major controlling factor for changes in benthic associations within the constraints of the adjacent species pool as it is directly linked to the organic matter content (food availability) which is one of the important factors in determining trophic complexity and species abundances (Knox 2001; Incera et al. 2006; Rodil et al. 2012). However, sediment organic matter is not the only structuring factor and other factors such as the beach morphodynamics also have an important role in structuring sandy beach communities (McLachlan \& Jaramillo 1995; McLachlan 1996; Defeo \& McLachlan 2005). Recent studies show that both physical as well as nutritional variables are important for the sandy beach community structure (Incera 
et al. 2006; Cisneros et al. 2011). Therefore, information on the responses of macrobenthic species on changing sediment characteristics is one of the crucial elements to assess the impact of beach nourishment on the macrobenthic community. Unfortunately, experimental studies on sediment preferences of sandy beach species are scarce and existing studies only examine sediment selection of higher trophic species such as flatfish (Gibson \& Robb 2000; Nasir \& Poxton 2001; Carl et al. 2008) while studies on the preferences of macrobenthos are rare (Speybroeck 2007).

Since profile beach nourishment mostly affects the high-intertidal beach as large amounts of sediment are first placed on the high shore and are than divided by bulldozers over the entire beach (Hanson et al. 2002), we examined the sediment preferences of the key macrobenthic species of the high-intertidal Scolelepis squamata - Eurydice pulchra community of the Belgian beach ecosystem (Van Hoey et al. 2004). Belgian beaches are characterized by gentle slopes and fine sediments and are thus generally considered to be dissipative (Degraer et al. 2003b). The selected species of the high-intertidal community of these dissipative beaches were the polychaete Scolelepis squamata, the isopod Eurydice pulchra and the two amphipods Bathyporeia pilosa and Bathyporeia sarsi. Scolelepis squamata is a suspension feeding polychaete (Dauer 1983) while the amphipods feed on epipsammic diatoms attached to the sand grains (Nicolaisen \& Kanneworff 1969). The isopod Eurydice pulchra is an aggressive and very mobile predator, feeding on polychaetes and crustaceans such as Bathyporeia pilosa, Bathyporeia sarsi and Scolelepis squamata (Jones 1968).

The aims of this study, investigating the sediment selection of sandy beach macrobenthos of dissipative sandy beaches, were (1) to examine the sediment preference of the four dominant macrobenthic species (Scolelepis squamata, Eurydice pulchra, Bathyporeia pilosa and Bathyporeia sarsi) of these beaches to formulate valuable recommendations for the used sediment in beach nourishment projects and (2) to study the effect of interspecific interactions in influencing this choice.

\section{Material and methods}

\subsection{Experimental design}

Sediment preference was examined for the four species, both in single-species and combined-species conditions. Besides the single-species treatments, several two-, three- and four-species combinations were experimentally studied (table 1) during the summer of 2011. Due to the high number of two- and three-species combinations possible, only the two-species combinations between species with different trophic positions or between possible competitors were tested. As the polychaete and the amphipods are known to feed on different food sources (Nicolaisen \& Kanneworff 1969; Dauer 1983), polychaeteamphipod combinations were thus not tested. Furthermore, only a limited number of three-species combinations were tested as the results of these treatments could not unequivocally indicate what 
species was the most influencing for possible preference changes. The experiment was conducted in a climate room at $19^{\circ} \mathrm{C}$, the summer temperature on Belgian sandy beaches, in a natural summer dark/night regime (16:8 $\mathrm{h}$ light/dark).

Table 1: Sediment preference treatments. Single-species (column 1) and combined-species treatments (column 24) where sediment preferences were tested for

\begin{tabular}{|c|c|c|c|}
\hline Single-species treatment & 2-species treatment & 3-species treatment & 4-species treatment \\
\hline Bathyporeia pilosa & $\begin{array}{l}\text { Bathyporeia pilosa- } \\
\text { Bathyporeia sarsi }\end{array}$ & $\begin{array}{l}\text { Bathyporeia pilosa- } \\
\text { Bathyporeia sarsi - } \\
\text { Scolelepis squamata }\end{array}$ & $\begin{array}{l}\text { Bathyporeia pilosa- } \\
\text { Bathyporeia sarsi - } \\
\text { Scolelepis squamata- } \\
\text { Eurydice pulchra }\end{array}$ \\
\hline Bathyporeia sarsi & $\begin{array}{l}\text { Eurydice pulchra- } \\
\text { Bathyporeia pilosa }\end{array}$ & & \\
\hline Scolelepis squamata & $\begin{array}{l}\text { Eurydice pulchra- } \\
\text { Bathyporeia sarsi }\end{array}$ & & \\
\hline Eurydice pulchra & $\begin{array}{l}\text { Eurydice pulchra- } \\
\text { Scolelepis squamata }\end{array}$ & & \\
\hline
\end{tabular}

The experimental organisms were released into round-shaped aquaria (cross-section $=30 \mathrm{~cm} ; \mathrm{h}=10$ $\mathrm{cm}$ ), subdivided into four quarters by metal partitions which prevented movement between sections via the sediment. Each section was covered with a layer of one of the four different sediment types, either naturally occurring on sandy beaches or used in current and future beach nourishment projects (fine: 125 - $180 \mu \mathrm{m}$; medium-fine: 180 - $250 \mu \mathrm{m}$; medium-coarse: 250 - $355 \mu \mathrm{m}$; coarse (outside the range of sediments naturally occurring on the beaches considered in this study): $355-500 \mu \mathrm{m}$ ). Each species treatment was replicated five times. Sediment depth was $4 \mathrm{~cm}$ and the seawater depth on top of the sediment was $5 \mathrm{~cm}$. Sediments remained submerged throughout the experiments, ruling out desiccation of experimental specimens. During the 48 hour experiment, the aquaria were constantly aerated but no food was added since experimental time was limited. Experiments were started at low tide and animals were released at random into the aquarium by pouring the organisms (submerged in a small amount of sea water) in a circular movement over the four subdivisions. As the experiment started at low tide when most species stay buried, a time lag of 15 minutes was respected after addition of the first species before adding the next species to allow every species to bury in the sediment. After 48 hours (ensuring several swimming cycles of the species at high tide), the experiment was terminated and all living individuals were extracted from each section and counted. During several subsequent weeks from May to July 2011, all species combinations were examined each time using new experimental organisms. 


\subsection{Collection of organisms, sand and sea water}

Beach sediment was collected at the beach of De Panne (Belgium; $2^{\circ} 33^{\prime} 24^{\prime \prime}$ E 51 $05^{\prime} 42^{\prime \prime} \mathrm{N}$ ) and after removal of organic matter by heating the sediment up to $450^{\circ} \mathrm{C}$, the sand was sieved over a sequence of sieves with mesh width of $125 \mu \mathrm{m}, 180 \mu \mathrm{m}, 250 \mu \mathrm{m}, 355 \mu \mathrm{m}$ and $500 \mu \mathrm{m}$. The sea water, originating from the same Belgian beach, was filtered over a $45 \mu \mathrm{m}$ filter to remove all fauna from the water.

All organisms were collected by sieving the beach sediment on the high-intertidal beach in De Panne. In the experimental treatments, natural densities of the macrobenthic species were used that ensured enough encounters to force active selection between sediment types (Speybroeck 2007): 150 individuals/treatment $\left(=2125\right.$ ind. $\left.\mathrm{m}^{-2}\right)$ for Bathyporeia pilosa; 70 individuals/treatment $\left(=991\right.$ ind. $\left.\mathrm{m}^{-2}\right)$ for Bathyporeia sarsi; 20 individuals/treatment $\left(=284\right.$ ind. $\left.\mathrm{m}^{-2}\right)$ for Scolelepis squamata and 10 individuals/treatment (=143 ind. $\mathrm{m}^{-2}$ ) for Eurydice pulchra.

In the multi-species treatments, total species densities were higher than in the single-species treatments, but as this actually reflects the field situation, this was expected to give valuable results. Indeed, the zonation patterns of the high-intertidal macrobenthos species show overlap (Degraer et al. 2003a; Degraer et al. 2003b), resulting in a higher overall species abundance on the beach. Before the start of the experiment, species stocks were left overnight to allow acclimatization of the experimental organisms.

\subsection{Data analysis}

The distribution of species was tested with a replicated G-test of goodness-of-fit (Sokal \& Rohlf 1995; Stoner \& Ottmar 2003). This test was used to examine whether the species showed a random distribution over the four sediment types offered. The null hypothesis states that the number of observations in each sediment is equal to the expected distribution, i.e. as a random distribution is hypothesized, the number of observations in each sediment type should be equal. The replicated G-test of goodness-of-fit has the advantage that the null hypothesis can be tested for each individual experiment (partial G's) but also for the pooled data set (Sokal \& Rohlf 1995). Heterogeneity G(Gh) (with [no. of replicates -1$] \times$ [no.of sediment types- 1] degrees of freedom) was calculated to assess heterogeneity among replicate treatments. Pooled G (Gp) (with no. of sediment types -1 degrees of freedom) tested the goodness of fit for the pooled data over all experimental replicates, and $\mathrm{Gt}$, the sum of $\mathrm{Gh}$ and $\mathrm{Gp}$ (with [df Gh] + [df Gp] degrees of freedom) tested whether the data as a whole fitted the expected distribution. In the combined-species treatments, the same G- test was used against the null hypothesis that species distribution was similar to the species distribution in the single-species experiments. 
The sediment selectivity was estimated by the Electivity index, $E^{\prime}$. $E^{\prime}$ is calculated per sediment type as: $E^{\prime}=\left(c_{i}-O_{i}\right) /\left(c_{i}+o_{i}\right)$ where $c_{i}$ is the species abundance in one sediment type and $o_{i}$ the expected abundance, in case of random distribution, for that sediment (Ivlev 1961). Positive E' values indicate a preference, negative ones a rejection (Hiddink et al. 2002).

\section{Results}

\subsection{Single species treatments}

The results of the G-test showed a significant sediment preference for all tested species (table 2 and 3). In detail, Bathyporeia pilosa clearly preferred the finer sediments since $87 \%$ of the experimental population of this amphipod was found in the sediments with a grain size smaller than $250 \mu \mathrm{m}$ (figure $1 \mathrm{~A}$ and table 2). As $42 \%$ of the experimental population of the related amphipod Bathyporeia sarsi was found in the sediment types with a grain size larger than $250 \mu \mathrm{m}$, Bathyporeia sarsi had a broader preference (figure $1 \mathrm{~B}$ and table 2). Scolelepis squamata was more divided over finer and coarser sediments, $30 \%$ of these polychaetes was even found in sediment with a grain size larger than $355 \mu \mathrm{m}$ (figure 1C) and table 2), whereas for Eurydice pulchra the sediment preference resembled the preference of Bathyporeia pilosa (figure 1D and table 2). The results of the G-tests for goodness of fit showed that replicates were heterogeneous for Bathyporeia pilosa and Eurydice pulchra. Nevertheless, the partial G's were highly significant $(p<0.001)$.

\subsection{Combined species treatments}

Sediment preferences of all tested macrobenthic species differed significantly between single-species and combined species conditions (table 2). Although replicates were heterogeneous for all tested species, the partial G's were highly significant $(p<0.001)$. In the presence of Eurydice pulchra, the Bathyporeia pilosa frequency of occurrence in the fine and medium-fine sediment decreased, while the frequency of occurrence in the medium-coarse sediment increased from $11 \pm 1 \%$ to $22 \pm 5 \%$ (figure $1 \mathrm{~A}$ ). In the presence of the related amphipod Bathyporeia sarsi, the Bathyporeia pilosa frequency of occurrence in the medium-fine sediment decreased from $45 \pm 3 \%$ to $25 \pm 4 \%$, while the frequency of occurrence of Bathyporeia pilosa in the two coarsest sediments increased (figure 1A). In the 3-species treatment, the Bathyporeia pilosa frequency of occurrence in the medium-fine sediment decreased to 28 $\pm 3 \%$, while the frequency of occurrence in the medium-coarse sediment increased (figure $1 \mathrm{~A}$ ) and in the

4-species treatment, there was a decrease of Bathyporeia pilosa frequency of occurrence in the fine sediment, while there was an increase in the medium-coarse and coarse sediments (figure $1 \mathrm{~A}$ ).

In the presence of Eurydice pulchra, a strong increase of Bathyporeia sarsi from $18.94 \pm 1.93 \%$ to $42.05 \pm$ $13.36 \%$ was observed in the medium-fine sediment, while a decrease was found in the fine and coarse 
sediments (figure 1B). In the presence of Bathyporeia pilosa, the sediment preference of Bathyporeia sarsi changed only slightly (figure $1 \mathrm{~B}$ ). The polychaete Scolelepis squamata showed a significant increase in the fine sediment from $13.33 \pm 4.16 \%$ in the single-species treatment to $29.23 \pm 4.10 \%$ in the 3 species treatment and even $34.16 \pm 8.48 \%$ in the 4 -species treatment (figure $1 \mathrm{C}$ ). Isopod frequency of occurrence increased in the coarse sediment from $13.11 \pm 4.19 \%$ to $27.56 \pm 7.58 \%$ and to $23.00 \pm$ $10.20 \%$ in the 3 - and 4-species treatments respectively (figure 1D).
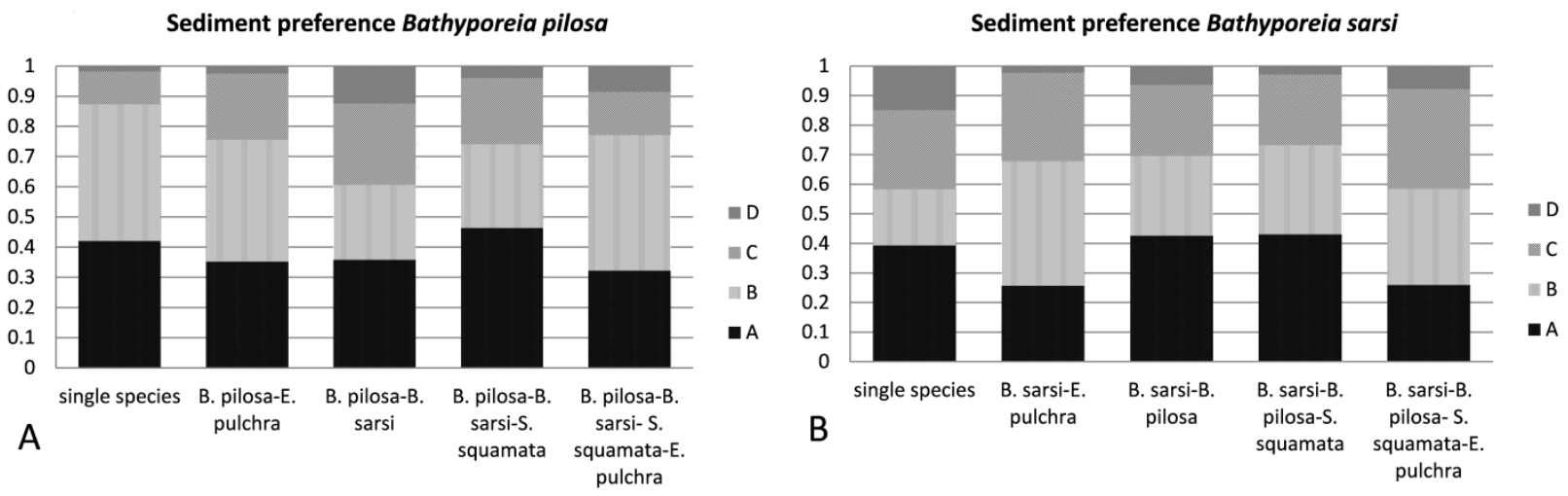

Sediment preference Scolelepis squamata
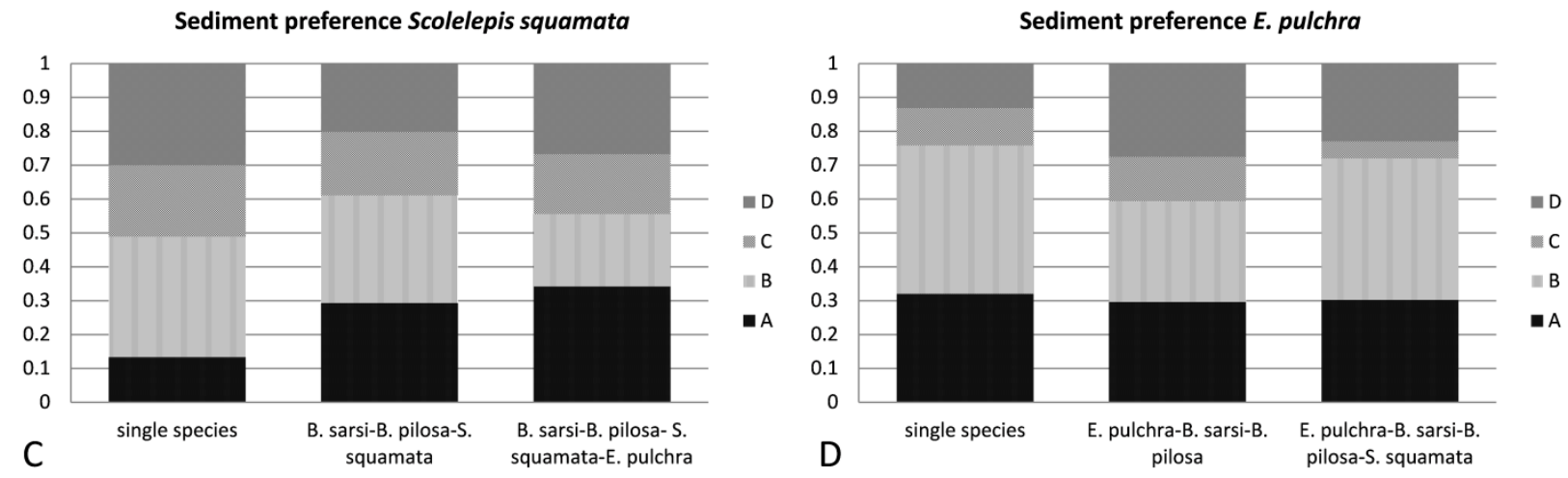

Figure 1: Sediment preference of Bathyporeia pilosa (A), Bathyporeia sarsi (B), Scolelepis squamata (C) \& Eurydice pulchra (D) in single-species- and combined-species conditions. X-axis: species treatments; Y-axis: average proportion of the experimental population in sediment types: A: $125-180 \mu \mathrm{m}$; B: $180-250 \mu \mathrm{m}$; C: $250-355 \mu \mathrm{m}$; D: $355-500 \mu \mathrm{m}$ 
Table 2: G-test results of the single-species and combined-species treatments of Bathyporeia pilosa, Bathyporeia sarsi, Scolelepis squamata and Eurydice pulchra

\begin{tabular}{|c|c|c|c|c|c|c|}
\hline Bathyporeia pilosa & Gt (df: 15) & $p(G t)$ & Gh (df: 12) & $p(G h)$ & $\mathrm{Gp}(d f: 3)$ & $p(G p)$ \\
\hline B. pilosa (single species treatment) & 435.31 & $<0.001$ & 56.85 & $<0.001$ & 378.47 & $<0.001$ \\
\hline B. pilosa-B. sarsi - S. squamata - E. pulchra & 290.79 & $<0.001$ & 183.71 & $<0.001$ & 107.08 & $<0.001$ \\
\hline B. pilosa - B. sarsi - S. squamata & 1008.08 & $<0.001$ & 883.89 & $<0.001$ & 124.18 & $<0.001$ \\
\hline B. pilosa-B. sarsi & 128.87 & $<0.001$ & 57.14 & $<0.001$ & 71.73 & $<0.001$ \\
\hline E. pulchra-B. pilosa & 108.01 & $<0.001$ & 84.06 & $<0.001$ & 23.95 & $<0.001$ \\
\hline Bathyporeia sarsi & Gt (df: 15) & $\mathrm{p}(\mathrm{Gt})$ & Gh (df: 12) & p(Gh) & Gp (df: 3) & $\mathrm{p}(\mathrm{Gp})$ \\
\hline B. sarsi (single species treatment) & 24.71 & 0.054 & 7.59 & 0.82 & 17.13 & $<0.001$ \\
\hline B. pilosa-B. sarsi-S. squamata-E. pulchra & 225.62 & $<0.001$ & 171.58 & $<0.001$ & 54.04 & $<0.001$ \\
\hline B. pilosa-B. sarsi - S. squamata & 100.13 & $<0.001$ & 32.91 & $<0.001$ & 67.22 & $<0.001$ \\
\hline B. pilosa - B. sarsi & 2331.39 & $<0.001$ & 59.79 & $<0.001$ & 2271.59 & $<0.001$ \\
\hline E. pulchra-B. sarsi & 276.71 & $<0.001$ & 172.83 & $<0.001$ & 103.87 & $<0.001$ \\
\hline Scolelepis squamanta & Gt (df: 15) & $p(G t)$ & Gh (df: 12) & $p(G h)$ & $\mathrm{Gp}(d f: 3)$ & $p(G p)$ \\
\hline S. squamata (single species treatment) & 20.19 & 0.16 & 9.32 & 0.68 & 10.88 & 0.012 \\
\hline B. pilosa - B. sarsi-S. squamata - E. pulchra & 107.22 & $<0.001$ & 77.93 & $<0.001$ & 29.29 & $<0.001$ \\
\hline B. pilosa - B. sarsi - S. squamata & 92.04 & $<0.001$ & 39.83 & $<0.001$ & 52.21 & $<0.001$ \\
\hline Eurydice pulchra & Gt (df: 15) & $\mathrm{p}(\mathrm{Gt})$ & Gh (df: 12) & $p(G h)$ & $\mathrm{Gp}(d f: 3)$ & $p(G p)$ \\
\hline E. pulchra (single species treatment) & 61.23 & $<0.001$ & 47.26 & $<0.001$ & 13.97 & 0.0029 \\
\hline B. pilosa-B. sarsi-S. squamata-E. pulchra & 88.11 & $<0.001$ & 64.13 & $<0.001$ & 23.98 & $<0.001$ \\
\hline B. pilosa-B. sarsi - E. pulchra & 43.08 & $<0.001$ & 34.95 & $<0.001$ & 8.13 & 0.043 \\
\hline
\end{tabular}

Table 3: Sediment selectivity based on the Electivity index

\begin{tabular}{lcccc}
\hline & $125-180 \mu \mathrm{m}$ & $180-250 \mu \mathrm{m}$ & $250-355 \mu \mathrm{m}$ & $355-500 \mu \mathrm{m}$ \\
\hline Bathyporeia pilosa & + & + & - & - \\
Bathyporeia sarsi & + & - & + & - \\
Eurydice pulchra & + & + & - & - \\
Scolelepis squamata & - & + & + & + \\
\hline
\end{tabular}

\section{Discussion}

\subsection{Species sediment preference}

The preference of Bathyporeia pilosa for the two sediment types with a grain size smaller than $250 \mu \mathrm{m}$, is in line with observed field preferences of this amphipod for sediment with a median grain size smaller than $250 \mu \mathrm{m}$ and even smaller than $210 \mu \mathrm{m}$ (Vader 1965; Vader 1966; Khayrallah \& Jones 1980; Persson 1982; Nicolaisen \& Kanneworff 1983). The field sediment preference of Bathyporeia sarsi for somewhat coarser sediment (Vader 1965) was also confirmed in this experimental study. While a previous study by Jones (1969) found a preference for coarser sediments, the isopod Eurydice pulchra preferred fine sediment in the current study. Since the pattern was found both in combined-species as well as in single- 
species conditions, the presence of prey species in the finer sediments could not explain this behavior. As Eurydice pulchra is a highly energetic swimmer (Alheit \& Naylor 1976), the preference for the finer sediment is likely to have been an active choice. The differences between studies are remarkable and differing experimental conditions can be an important cause. However, a former experimental study in the same laboratory and under similar experimental conditions as the current study showed a preference for coarse sediment (Vandewalle 2009). The only clear difference between these studies is the origin of the experimental organisms. While the species used in this study were gathered on the dissipative beach of De Panne, the used species in the study of Vandewalle (2009), were collected on the dissipative beach of Raversijde but sediment did not differ significantly between these two beaches. The statistical analysis of this study did however indicate that replicates were heterogeneous and this can hamper a clear interpretation of the sediment preference. Hence, the sediment preference of Eurydice pulchra might have been less specific than for other sandy beach species and a broad tolerance could be suggested for the isopod. This conclusion is supported by the cosmopolitan occurrence of Eurydice pulchra, both on fine-grained dissipative beaches (Degraer et al. 2003b) as well as on coarse-grained reflective beaches (Rodil et al. 2006).

The most striking result in this study was the preference of the polychaete Scolelepis squamata for both medium-fine as well as coarse sediment, also found by Speybroeck (2007). While this spionid polychaete inhabits fine to medium sediments on West European dissipative beaches (Degraer et al. 2003b; Janssen \& Mulder 2005), it is a rather cosmopolitan species inhabiting both fine-grained as well as coarse-grained sediments (Dahl 1971; Hartmann-Schröder 1996; Van Hoey et al. 2004), which is in accordance with the results of our experiments.

\subsection{Recommendations for beach nourishment of West European sandy beaches}

Although differences were found between preferences in single-species and combined-species conditions, general recommendations for nourishment could be made based on the results of this study. All studied species preferred sediment with a median grain size smaller than $250 \mu \mathrm{m}$ (figure 2). Sediment with a median grain size between $250 \mu \mathrm{m}$ and $355 \mu \mathrm{m}$ negatively influenced the presence of the amphipod Bathyporeia pilosa and the isopod Eurydice pulchra, while coarse sediment (355-500 $\mu \mathrm{m})$ negatively influenced all species except the polychaete Scolelepis squamata (figure 2). 


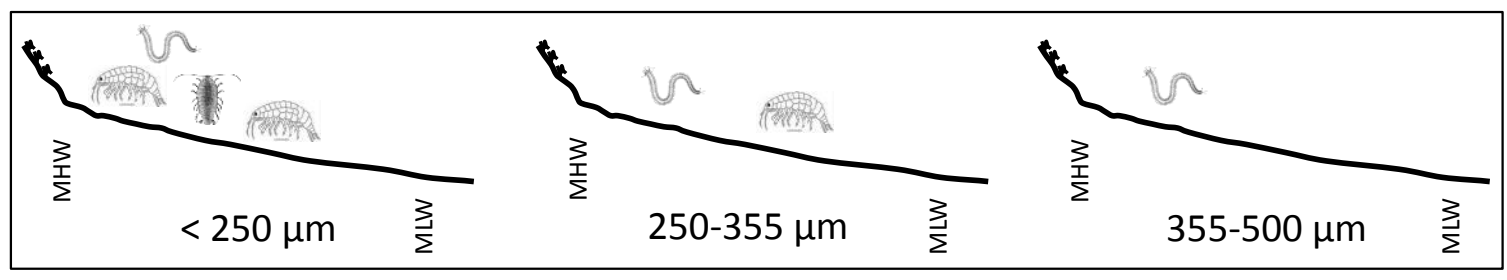

Figure 2: Hypothetical high-intertidal macrobenthos community after beach nourishment using three sediment types

The results of this experimental study on sediment preferences of the most dominant species of dissipative sandy beaches do not immediately imply field mortality or a decrease in field recruitment when the habitat is altered due to nourishment projects. However, observations and monitoring after nourishment are showing that when the habitat of sandy beaches is altered towards less favorable conditions, some species do not recolonize the nourished beach or only recolonize the beach in lower abundances after several months (Schlacher et al. 2012). As the intertidal sandy beach environment is a dynamic habitat and sandy beach animals are very mobile, they are likely to avoid those habitats that do not satisfy their preferences.

While other factors like beach profile, inundation time and organic matter are also important in determining the outcome of a nourishment, repeated beach nourishment projects with coarse sediments will inevitably lead to habitat loss for macrobenthos on dissipative beaches, especially for those species preferring fine sediments like Bathyporeia pilosa. As a result, the macrobenthos diversity and abundance will decrease and beaches will in essence be inhabited by extremely opportunistic species like the polychaete Scolelepis squamata (figure 2) as was also found after dredging events (Rosa \& Bemvenuti 2006). This polychaete will probably suffer least from nourishment events as it can quickly recolonize nourished beaches due to their pelagic larvae, and will not suffer from the presence of coarse sediment. In addition, when nourishment projects are characterized by coarse sediment and steep slopes, there is a risk of not only decreasing biodiversity but also of causing entire community shifts. Indeed, macrobenthos communities in flat, fine-grained dissipative beaches differ greatly from communities in coarse-grained, steeper reflective beaches (McLachlan 1990; Defeo et al. 1992; Defeo \& McLachlan 2011) and the alternation of the morphodynamics of a beach may thus lead to community shifts. For the West-European dissipative beaches this evolution would cause an important loss of biodiversity since dissipative beaches are known to be richer than reflective ones (McLachlan et al. 1996a). 


\subsection{Sediment preferences and species interactions on sandy beaches}

Examining biotic interactions by sediment selection experiments is an indirect approach (Dugan et al. 2004), but previous research has shown its merit (Defeo et al. 1997). Hence, the results of this sediment selection experiment can give insights in the role of biotic interactions on dissipative sandy beaches. Bathyporeia pilosa significantly changed its sediment preference towards the coarser sediments, where densities of the related amphipod Bathyporeia sarsi were lower in combined-species conditions. These changes seemed to be steered by interspecific competition with Bathyporeia sarsi. Adversely however, Bathyporeia sarsi did not seem to actively avoid Bathyporeia pilosa and was thus probably not affected by competition of Bathyporeia pilosa. Since former experiments on competition between the cooccurring amphipods Bathyporeia pilosa and Bathyporeia sarsi were not decisive on the role of interspecific competition (Van Tomme et al. 2012a), this sediment selection experiment could gain a better insight into their segregated zonation pattern on the intertidal beach (Speybroeck et al. 2008b). Interspecific competition usually has asymmetric effects (Connell 1983; Schoener 1983), especially in the marine intertidal zone, with larger species being competitively dominant (Paine 1980; Schoener 1983; Brown \& Maurer 1986; van Riel et al. 2007). In this study, the competitive superiority of the largest amphipod, Bathyporeia sarsi (Speybroeck et al. 2008b), was indicated, suggesting that asymmetric interspecific competition can play a structuring role on dissipative sandy beaches.

Predation by the predator Eurydice pulchra could also be hypothesized to be an important factor in influencing species distribution on sandy beaches. In combined-species treatments where the predator Eurydice pulchra was present, a clear avoiding behavior could be inferred from the data since the amphipods and especially Bathyporeia pilosa moved to sediments with the lowest density of Eurydice pulchra.

Finally, it was clear that the amphipod Bathyporeia pilosa was suffering most from biotic interactions and this could explain its small realized niche on the high-intertidal sandy beach. Although the morphology of the co-occurring Bathyporeia sarsi is not highly different at first sight, competition and predation did not seem to have a clear effect on the behavior of this larger amphipod (Speybroeck et al. 2008b), as could be reflected in its occupancy of a wider zone on the beach compared to Bathyporeia pilosa (Speybroeck et al. 2008b).

\section{Conclusions}

The results of this sediment selection experiment show that while the amphipods Bathyporeia pilosa and Bathyporeia sarsi were preferring fine to medium-fine sediment, the opportunistic polychaete Scolelepis squamata preferred coarse sediment. The isopod Eurydice pulchra preferred fine sediment but these results were not in accordance with former field and experimental studies. Additionally, interspecific 
competition with the sympatrically occurring amphipod Bathyporeia sarsi was found to change the sediment selection of the amphipod Bathyporeia pilosa towards the coarser sediments where Bathyporeia sarsi occurred in lower frequencies.

To mitigate the impact of beach nourishment projects on intertidal sandy beaches and to assure a swift recolonization of the nourished beach by the original sandy beach community, the use of sediment that resembles the initial beach sediment, is therefore strongly encouraged. The use of coarse sediments is likely to have a negative effect on some of the dominant macrobenthic species of the high-intertidal on fine-grained beaches. Therefore, both technical as well as ecological aspects of the sandy beach ecosystem should be considered in beach nourishment programmes to assure its highly valuable ecosystem role.

\section{Acknowledgments}

The first author acknowledges an aspirant grant provided by FWO-Vlaanderen (Belgium). Additional funding was provided by the Special Research Fund of the Ghent University (BOF-GOA 01GA1911W). We also want to thank all the helping hands in the field for the collection of the test organisms. 